\title{
Correos electrónicos y mensajes de funcionarios públicos como información pública
}

\author{
Miguel EnriQue Morachimo Rodríguez ${ }^{(*)}$ \\ Abogado por la Pontificia Universidad Católica del Perú. \\ Máster en Derecho, Ciencia, y Tecnología por la Universidad de Stanford \\ Dilmar Villena Fernández Baca \\ Bachiller en Derecho por la Pontificia Universidad Católica del Perú.
}

SUMARIO:

I. La Ley de Transparencia y acceso a la información pública en Perú: ¿qué es información pública y cuál es el régimen de excepciones?

1. Información secreta.

3. Información confidencial.

II. Contenido de los correos electrónicos y aplicaciones de mensajería electrónica de funcionarios públicos: ¿información pública?

III. Situación en Perú.

1. Reglamentación.

1.1. Decreto Supremo $\mathrm{N}^{\circ} 019-2017-\mathrm{JUS}$.

1.2. Decreto Supremo N ${ }^{\circ} 011-2018-J U S$.

2. Posición de las entidades.

2.1. Dirección General de Transparencia, Acceso a la Información Pública y Protección de Datos Personales.

2.2. Defensoría del Pueblo.

IV. Sobre la inconstitucionalidad del actual Reglamento de Transparencia.

Declaración de conflicto de interés: El autor es demandante en un proceso de Acción Popular sobre la constitucionalidad del Artículo 16-A del Reglamento de la Ley de Transparencia, precisamente discutido en este artículo. 


\section{RESUMEN:}

El marco normativo de la protección de datos de funcionarios públicos en servidores propiedad del Estado es muy ambiguo, e incluso podría ser considerado inconstitucional. Los autores desarrollan argumentos por los que opinan que la información, mensajes y comunicaciones contenidas en servidores públicos debería ser accesible por el público, en virtud del derecho a la información.

Palabras clave: transparencia, datos personales, información pública, funcionarios públicos, mensajes, correo electrónico.

\footnotetext{
ABSTRACT:

The law regarding protection of public servants' data in government-owned servers is ambiguous and could even be considered unconstitutional. The authors develop ideas with which they argue if information, messages and communications inside government-owned servers should be accessible to the public, by virtue of the right to information.

Keywords: transparency, personal data, public information, public servants, messages, email.
}

I. LA LEY DE TRANSPARENCIA Y ACCESO A LA INFORMACIÓN PÚBLICA EN PERÚ: ¿QUÉ ES INFORMACIÓN PÚBLICA Y CUÁL ES EL RÉGIMEN DE EXCEPCIONES?

El principio constitucional de transparencia no está recogido de manera expresa en nuestra Constitución. Sin embargo, éste sí se encuentra de manera implícita en nuestro texto constitucional y se configura a partir de los artículos $3^{1}, 43^{2}$ y $45^{3}$ de la Constitución. Estos artículos reconocen que el poder emana del pueblo y, por ende, que "éste debe ejercerse no solo en nombre del pueblo, sino para él"1". Como consecuencia, todo acto producto del poder puede y debe ser conocido por el pueblo. Al transparentar y hacer conocible cómo se ejerce el poder, se da un giro en la concepción del actuar del Estado pues, en contraposición a la "cultura del secreto" — cultura según la cual la Administración se creía dueña de la información ${ }^{5}$ - y de la mano con el principio de publicidad,

"(...) se comprende que toda información en poder del Estado o de las personas jurídicas bajo el régimen privado que prestan servicios públicos o ejerzan función administrativa, en virtud de concesión, delegación o autorización, es en principio pública. Todo documento que haya sido confeccionado bajo el financiamiento del presupuesto público es en principio público. (...)"

De esta manera, la información relativa al manejo de la cosa pública es, aunque pueda sonar redundante, pública; y por ello tiene que estar al alcance de todos en miras a "posibilitar la ple-

1. "Artículo $3^{\circ}$. La enumeración de los derechos establecidos en este capítulo no excluye los demás que la Constitución garantiza, ni otros de naturaleza análoga o que se fundan en la dignidad del hombre, o en los principios de soberanía del pueblo, del Estado democrático de derecho y de la forma republicana de gobierno."

2. "Artículo 43․ La República del Perú es democrática, social, independiente y soberana. (...)"

3. "Artículo $45^{\circ}$. El poder del Estado emana del pueblo. Quienes lo ejercen lo hacen con las limitaciones y responsabilidades que la Constitución y las leyes establecen. (...)"

4. Expediente $\mathrm{N}^{\circ}$ 00565-2010-PHD/TC, fundamento jurídico 5.

5. Expediente $\mathrm{N}^{\circ}$ 04912-2008-PHD/TC, fundamento jurídico 4.

6. Expediente $\mathrm{N}^{\circ}$ 04912-2008-PHD/TC, fundamento jurídico 4 
na eficacia de los principios de publicidad y transparencia"n.

Este criterio también ha sido recogido por la Corte Interamericana de Derechos Humanos en el conocido caso Claude Reyes y otros v. Chile: el actuar del Estado debe estar regido por los principios de publicidad y transparencia logrando, a través de estos, el control democrático de la gestión pública y la responsabilidad de los funcionarios públicos ${ }^{8}$. La Carta Democrática Interamericana, aprobada el 11 de septiembre del 2001 en Lima, también indica en su artículo 4 que es "componentes fundamentales del ejercicio de la democracia la transparencia de las actividades gubernamentales (...)".

Nuestra Ley de Transparencia y Acceso a la Información Pública, cuyo Texto Único Ordenado se aprobó mediante Decreto Supremo N ${ }^{\circ} 043-$ 2003-PCM, —en adelante, la "Ley"-, desarroIla dicho principio constitucional y el derecho fundamental derivado de éste: el derecho de acceso a la información pública. El artículo 3 inciso 1 de dicha Ley reconoce una presunción de publicidad de la información en manos del Estado: "Toda información que posea el Estado se presume pública, salvo las excepciones expresamente previstas".

Así, se configura una presunción —que admite prueba en contrario-y que solo puede ser derrotada si la información entra dentro del régimen de excepciones que prevea la Ley. De esta manera, desarrollando el régimen de las excepciones, el artículo 18 establece que

"Los casos establecidos en los artículos 15, 16 y 17 son los únicos en los que se puede limitar el derecho al acceso a la información pública, por lo que deben ser interpretados de manera restrictiva por tratarse de una limitación $a$ un derecho fundamental. No se puede es- tablecer por una norma de menor jerarquía ninguna excepción a la presente Ley." - $\mathrm{el}$ subrayado es nuestro-.

La regulación de las excepciones gira en torno a las siguientes ideas: la regulación de estas debe ser expresa, y no pueden estar establecidas en normas de menor jerarquía a la de la Ley de Transparencia y Acceso a la Información Pública. Ello es conforme con el inciso 5 del artículo 2 de la Constitución que enuncia, respecto del ejercicio del derecho de acceso a la información pública, que "[s]e exceptúan las informaciones que afectan la intimidad personal y las que expresamente se excluyan por ley o por razones de seguridad nacional."

Por otro lado, la Ley también determina qué se debe considerar como información de acceso público:

\section{"Artículo 10.- Información de acceso público}

Las entidades de la Administración Pública tienen la obligación de proveer la información requerida si se refiere a la contenida en documentos escritos, fotografías, grabaciones, soporte magnético o digital, o en cualquier otro formato, siempre que haya sido creada u obtenida por ella o que se encuentre en su posesión o bajo su control.

Asimismo, para los efectos de esta Ley, se considera como información pública cualquier tipo de documentación financiada por el presupuesto público que sirva de base a una decisión de naturaleza administrativa, así como las actas de reuniones oficiales."

De dicha norma podemos establecer que cierta información es pública y, por lo tanto, es de acceso público, independientemente de su formato o soporte, si:

7. Expediente $\mathrm{N}^{\circ}$ 01797-2002-PHD/TC, fundamento jurídico 2.

8. Sentencia de la Corte Interamericana de Derechos Humanos en el caso Claude Reyes y otros vs. Chile, de fecha 19 de setiembre de 2006, fundamentos jurídicos 86 y 87 . 
a) Ha sido creada u obtenida por una entidad pública; o,

b) Se encuentra en posesión o bajo control de una entidad pública; o,

c) Si la información es financiada por el presupuesto público y sirva de base a una decisión de naturaleza administrativa; 0 ,

d) Es un acta de reunión oficial.

Para la Ley, no es importante en qué soporte está la información, si esta es digital o consta en un documento físico, entre otros. Lo trascendente para determinar la naturaleza pública de cierta información es que haya sido creada, obtenida, financiada o se encuentre en posesión de una entidad pública. Siguiendo esta lógica es que se determina en la propia Ley cuáles serían las excepciones: de acuerdo a nuestra norma, contamos con información secreta, información reservada e información confidencial.

Las excepciones se sustentan de la siguiente manera:

\section{Información secreta.}

De acuerdo con el artículo 15 del Texto Único Ordenado-TUO de la Ley, es información secreta aquella que se sustente en razones de seguridad nacional y que, además,

"(...) tenga como base fundamental garantizar la seguridad de las personas y cuya revelación originaría riesgo para la integridad territorial y/o subsistencia del sistema democrático, así como respecto a las actividades de inteligencia y contrainteligencia del CNI dentro del marco que establece el Estado de Derecho en función de las situaciones expresamente contempladas en esta Ley".

\section{Información reservada.}

Esta sería información que, debido a razones de seguridad nacional en el ámbito del orden interno, tiene por finalidad "prevenir y reprimir la criminalidad en el país y cuya revelación puede entorpecerle"s; así como la información "cuya revelación originaría un riesgo a la seguridad e integridad territorial del Estado y la defensa nacional en el ámbito externo, al curso de las negociaciones internacionales y/o la subsistencia del sistema democrático".

\section{Información confidencial.}

Esta es información que contenga consejos o similares que sean producidas como parte de un proceso deliberativo y consultivo previo a la toma de una decisión de gobierno; la protegida por secreto bancario, tributario, comercial, etcétera; información de procedimientos sancionadores en trámite; la elaborada por asesores jurídicos cuya publicidad pueda revelar estrategias en procedimientos administrativos o judiciales; la referida a datos personales; y aquella que esté exceptuada expresamente por la Constitución o por una ley aprobada por el Congreso de la República.

Como se puede observar, el régimen de excepciones se fundamenta en el contenido de información, mas no en su soporte. No importa si la información consta en un documento físico, en un archivo digital o en cinta de video, lo relevante es que si dicha información gira en torno a, por ejemplo, ubicaciones de bases militares, no será información de acceso público.

Llegados a este punto, y en torno al régimen de excepciones del derecho de acceso a la información pública, podemos sacar las siguientes conclusiones: (a) en tanto limitan un derecho fundamental, las excepciones deben ser interpretadas de manera restrictiva; (b) solo se puede establecer excepciones a través de una norma con rango de ley; y, (c) las excepciones versan sobre el contenido de la información y no de su soporte.

Teniendo claros estos puntos en torno al régimen de excepciones, cabe analizar sobre si la

9. Artículo 16 del TUO de la Ley. 
información contenida en los correos electrónicos de funcionarios públicos y aplicaciones de mensajería electrónica de estos es información pública.

\section{CONTENIDO DE LOS CORREOS ELECTRÓ- NICOS Y APLICACIONES DE MENSAJERÍA ELECTRÓNICA DE FUNCIONARIOS PÚBLI- COS: ¿INFORMACIÓN PÚBLICA?}

Para determinar si la información contenida en los correos electrónicos y aplicaciones de mensajería electrónica de funcionarios públicos es de acceso público, creemos importante volver a señalar cuáles son los criterios para determinar si cierta información es información pública. Para efectos de este supuesto, únicamente tendremos en cuenta los siguientes criterios (a) si la información ha sido creada u obtenida por una entidad pública; $y$, (b) si esta se encuentra en posesión o bajo control de una entidad pública.

Cuando se crea un servidor o usuario para cuentas de correo electrónico institucional, éstos y la información que estos contienen se almacenan en las computadoras de los funcionarios públicos que laboran en la entidad. Lo mismo sucede con aplicaciones de mensajería electrónica. En este sentido, en la medida que la información estaría bajo posesión o bajo control de una entidad, dicha información sería de acceso público. De la misma manera, si la aplicación de mensajería instantánea se encuentra instalada en un teléfono móvil financiado por el presupuesto público o utilizan presupuesto público para realizar el pago por el intercambio de datos, también caería también dentro del supuesto de información de acceso público.

Una vez establecido que esta información es de acceso público, cabe analizar cuál es la relación de dicha información con el derecho al secreto e inviolabilidad de las comunicaciones. El artículo 2 inciso 10 de nuestra Constitución dispone que
“(...) Las comunicaciones, telecomunicaciones o sus instrumentos sólo pueden ser abiertos, incautados, interceptados o intervenidos por mandamiento motivado del juez, con las garantías previstas en la ley. Se guarda secreto de los asuntos ajenos al hecho que motiva su examen. (...)".

Sobre el particular, el Tribunal Constitucional peruano ha señalado en reiterada jurisprudencia ${ }^{10}$ que el mencionado derecho "prohíbe que las comunicaciones y documentos privados de las personas sean interceptados o conocidos por terceros ajenos a la comunicación misma". En este sentido, dicho derecho se ve afectado "cuando se aprehende la comunicación (...), como cuando se accede al conocimiento de lo comunicado, sin encontrarse autorizado para él"11. De este desarrollo, cabe llamar la atención que el mencionado derecho prohíbe el acceso a comunicaciones y documentos privados. Como tuvimos oportunidad de exponer previamente, la información contenida en los correos electrónicos institucionales de funcionarios públicos y aplicaciones de mensajería electrónica es información pública. Por ello, en principio, esta información no estaría dentro del ámbito de protección del derecho a la inviolabilidad de las comunicaciones y documentos privados.

Es cierto que hay quienes pueden sostener que los servidores públicos son trabajadores del Estado y que, de acuerdo a jurisprudencia del Tribunal Constitucional, los trabajadores gozan de la protección del secreto e inviolabilidad de sus comunicaciones. En efecto, el Tribunal Constitucional ha tenido oportunidad de afirmar que

"(...) puede alegarse que la fuente o el soporte de determinadas comunicaciones y documentos le pertenecen a la empresa o entidad en la que un trabajador labora, ello no significa que la misma pueda arrogarse en forma exclusiva y excluyente la titularidad de tales comunicaciones y documentos, pues con ello evidente-

10. Expediente $\mathrm{N}^{\circ}$ 01149-2018-PHC/TC, fundamento jurídico 7 y Expediente $\mathrm{N}^{\circ}$ 00867-2011-PA/TC, fundamento jurídico 2.

11. Expediente $\mathrm{N}^{\circ}$ 02863-2002-PA/TC, fundamento jurídico 3. 
mente se estaría distorsionando el esquema de los atributos de la persona, como si estos pudiesen de alguna forma verse enervados por mantenerse una relación de trabajo. ${ }^{\text {"2 }}$

No obstante, sobre ello cabe realizar las siguientes precisiones. En primer lugar, el propio Tribunal ha indicado que

“(...) La información o los datos (totales o parciales) registrados en documentos que por cualquier medio se encuentren sujetos (total o parcialmente) al principio de transparencia no se encuentran protegidos por el derecho al secreto de los documentos $y$, en consecuencia, no pesa sobre terceras personas el deber jurídico de mantener la reserva o confidencialidad de los mismos." ${ }^{\text {"3 }}$ - el subrayado es nuestro-.

Asimismo, un trabajador privado goza de una esfera de protección más amplia que un trabajador o servidor público. En efecto, el mencionado Alto Tribunal también tuvo oportunidad de indicar que "en una sociedad democrática los funcionarios y servidores públicos están más expuestos al escrutinio y a la crítica que las demás personas" 14 . En dicho caso, el Colegiado se pronunció en torno al derecho a la intimidad de funcionarios públicos y, en esa línea, sostuvo que:

"(...) el umbral de protección se ve reducido debido a que dichas personas, desde el momento en que han decidido asumir cargos públicos, se exponen, de manera voluntaria, a un mayor escrutinio público acerca del modo en que ejercen la función (...) [por lo tanto] es admisible -e incluso deseable- que a partir del ejercicio legítimo del derecho a la libertad de expresión, por ejemplo, pueda criticarse el desempeño de un funcionario o servidor público.
Esto responde a la necesidad misma que tiene la sociedad de informarse y de formarse un criterio sobre el manejo de la cosa pública"n5. -el subrayado es nuestro-.

Siguiendo dicha lógica, en la medida que el umbral de protección de los servidores públicos se ve reducido, sería admisible y deseable, que a partir del ejercicio del derecho de acceso a la información pública se pueda conocer el manejo de la cosa pública. Al momento que una persona toma la decisión de asumir un cargo público se expone, de manera voluntaria, a una mayor observancia y vigilancia pública, lo que incluye que las comunicaciones que realiza a través de sus cuentas institucionales sean de acceso público.

De esta manera, podemos concluir que la información contenida en las cuentas de correos electrónicos institucionales de funcionarios públicos y en las aplicaciones de mensajería electrónica es información pública. Esta información no cabe dentro del ámbito de protección del derecho al secreto e inviolabilidad de las comunicaciones. Asimismo, el servidor público, en su condición de tal y por haber asumido voluntariamente dicha condición, se encuentra expuesto a un nivel mayor de escrutinio y su ámbito de protección está reducido por el interés público que, en una sociedad democrática, existe por conocer y fiscalizar el manejo de los asuntos públicos.

Dicho esto, cabe analizar cuál es la situación sobre el particular en nuestro país.

\section{SITUACIÓN EN PERÚ}

Como expusimos previamente, para determinar la calidad de una información como pública o no, la Ley no diferencia en el soporte de esta.

12. Expediente $\mathrm{N}^{\circ}$ 01058-2004-PA/TC, fundamento jurídico 18.

13. Expediente $\mathrm{N}^{\circ}$ 02976-2012-PA/TC, fundamento jurídico 27.

14. Expediente 03079-2014-PA/TC, fundamento jurídico 60.

15. Ibíd., fundamentos jurídicos 61 y 62 . 
Cuando cierta información cumple los requisitos para ser pública, la única manera de sustraerla del acceso público es que quepa dentro de una de las excepciones establecidas en la Ley. Estas excepciones, además, tienen su justificación en el contenido de la información.

El Reglamento de la Ley, Decreto Supremo $N^{\circ}$ 072-2003-PCM —en adelante, el "Reglamento"-, al momento de su promulgación no hacía especificaciones en torno a si la información contenida en correos electrónicos y aplicaciones de mensajería electrónica de funcionarios públicos es información de acceso público o no. No obstante, dicha situación cambió en setiembre de 2017.

\section{Reglamentación.}

\subsection{Decreto Supremo $N^{\circ} 019-2017-J U S$.}

A través del Decreto Supremo N 019-2017-JUS, publicado el 15 de septiembre de 2017, se introdujo una modificación al Reglamento. En este se incorporaba el artículo 16-A cuyo tenor es el siguiente:

"Artículo 16-A.- Denegatoria de acceso y procesamiento de datos preexistentes

La información contenida en correos electrónicos o en aplicaciones de mensajería electrónica de los funcionarios públicos no es de acceso público."

Como podemos observar, el Reglamento optó por regular el acceso a la mencionada información estableciendo una prohibición absoluta: en ningún caso la información contenida en correos electrónicos o en aplicaciones de mensajería electrónica de los funcionarios públicos es de acceso público.

\subsection{Decreto Supremo $N^{\circ} 011-2018-J U S$.}

No obstante, dicha disposición no estaría vigente mucho tiempo. El 14 de noviembre de 2018 se publicó el Decreto Supremo № 011-2018-JUS que modificó la redacción de dicho artículo de la siguiente manera:
"Artículo 16-A.- Información contenida en correos electrónicos

La información contenida en correos electrónicos de los funcionarios y servidores públicos es de acceso público, siempre que se trate de información institucional de naturaleza pública. El pedido de información debe ponerse en conocimiento del funcionario o servidor público titular del correo electrónico, quién debe proporcionar la información solicitada. No es de acceso público la información contenida en correos electrónicos que tengan carácter de secreta, reservada y confidencial, de acuerdo a lo previsto en los artículos 15, 16 y 17 del Texto Único Ordenado de la Ley $N^{\circ}$ 27806, Ley de Transparencia y Acceso a la Información Pública, aprobado por Decreto Supremo $N^{\circ}$ 043-2003-PCM."

Se pasó, pues, de un régimen de prohibición absoluta a uno en el que se determinaba que si la información es "institucional de naturaleza pública" — sic - sería de acceso público. Además, se establece que es el propio funcionario o servidor público quien debe proporcionar la información solicitada.

Como era de esperar, estas modificaciones llamaron la atención de distintas entidades del Estado quienes, preocupados por el régimen de transparencia en nuestro Estado, emitieron sus pareceres -en especial, en torno a la primera modificación-. Pasemos a exponer brevemente cuál fue su posición.

\section{Posición de las entidades.}

2.1. Dirección General de Transparencia, Acceso a la Información Pública y Protección de Datos Personales.

La Dirección General de Transparencia, Acceso a la Información Pública y Protección de Datos Personales —en adelante, la "Dirección" — tuvo oportunidad de interpretar la primera formulación del artículo 16-A. Abordando dicho aspecto, a diferencia de la posición nuestra, la Dirección entiende que el derecho al secreto y a la inviolabilidad de las comunicaciones sí com- 
prende a las comunicaciones y documentos contenidos en correos electrónicos- que provengan de fuente institucional ${ }^{16}$. Sin embargo, ello "no es óbice para señalar que este contenido impide el acceso a la información de naturaleza pública que puedan poseer o albergar estos medios técnicos [los correos electrónicos] ${ }^{\text {n77. }}$.

Así, afirma que queda excluida cualquier interpretación de la norma que esté orientada a la exclusión absoluta de la información contenida en los correos electrónicos o aplicaciones de mensajería electrónica de funcionarios públicos. Así, opta por entender que la interpretación a dar al artículo 16-A es que la información contenida en correos electrónicos o en aplicaciones de mensajería electrónica de los funcionarios públicos no es de acceso público siempre que esta sea secreta, reservada o confidencial ${ }^{18}$.

No obstante ello, la Dirección concluye afirmando que es el propio funcionario público titular de la cuenta de correo electrónico el que brindará su consentimiento o no para la entrega de información cuando esta sea solicitada. Así, el servidor, luego de verificar si la información contenida en los correos electrónicos cabe dentro de algún supuesto establecido en la Ley, debe dejar por escrito su consentimiento; de no existir este, "está prohibida la entrega de información al solicitante $e^{\prime \prime 9}$.

En buena cuenta, si bien la Dirección considera que no es una interpretación constitucional- mente viable el considerar que toda la información contenida en los correos electrónicos y aplicaciones de mensajería electrónica no es de acceso público, establece un procedimiento distinto al de la Ley: que sea el propio funcionario titular el que determinará si se entrega o no la información. Como pudimos observar, la modificación al artículo 16-A recoge el espíritu de esta opinión consultiva. Como expondremos con mayor detalle de manera posterior, esta posición nos parece también de dudosa constitucionalidad.

\subsection{Defensoría del Pueblo.}

La Defensoría del Pueblo, a través del Informe de Adjuntía 001-2019-DP/AAC analizó ambos Decretos Supremos. Así, a grandes rasgos sostuvo que el incluir el artículo 16-A en el Reglamento no hace viable el combatir riesgos de corrupción en el Estado ${ }^{20}$. El mencionado artículo vulnera el principio de transparencia y el de máxima publicidad ya que "promueve el secretismo de aquella información que se encuentra almacenada en las cuentas electrónicas institucionales de los/as funcionarios/as públicos/as"21.

Asimismo, la Defensoría del Pueblo considera que esta norma no cumple con los estándares establecidos por la Organización de los Estados Americanos para limitar el acceso a la información pública y, asimismo, es innecesaria porque nuestro régimen actual ya cuenta con parámetros para determinar cuándo cierta información es pública o $\mathrm{no}^{22}$.

16. Dirección General de Transparencia, Acceso a la Información Pública y Protección de Datos Personales. Opinión Consultiva Nº51-2018-DGTAIPP, fundamento jurídico 39.

17. Ibíd.

18. Ibíd., fundamentos jurídicos 64 y 65 .

19. Ibíd., fundamento jurídico 72 , numeral (ii), inciso 2.

20. Defensoría del Pueblo. Informe de Adjuntía Nº01-2019-DP/AAC, 29.

21. Ibíd., 30.

22. Ibíd., 31. 
El mencionado organismo constitucional también se pronunció respecto de la modificación realizada al artículo 16-A posteriormente. En efecto, considera llamativo que se establezca que sea el propio funcionario público el que decida si cierta información es de acceso público y que este Reglamento también resulta insuficiente porque se debe desarrollar obligaciones en torno a la conservación de información contenida en correos electrónicos, entre otros ${ }^{23}$.

Finalmente, la Defensoría del Pueblo también explicó su parecer en torno al pronunciamiento emitido por la Autoridad Nacional de Transparencia y Acceso a la Información Pública. Sobre el particular, sostuvo que la mencionada opinión consultiva "introduce criterios, como el consentimiento del titular de la cuenta electrónica y la capacidad informática de la entidad, que contravienen el derecho de acceso a la información pública $y$, por consiguiente, no elimina los vicios de inconstitucionalidad advertidos en el primer párrafo del controvertido artículo $16-A^{\prime 24}$.

\section{SOBRE LA INCONSTITUCIONALIDAD DEL ACTUAL REGLAMENTO DE TRANSPA- RENCIA}

Nosotros consideramos que el artículo 16-A, tanto como en su redacción original como en su redacción vigente, es inconstitucional. Consideramos que la primera redacción era inconstitucional e ilegal porque iba en contra de una disposición expresa de la propia Ley: el artículo 18 establece que no se puede establecer excepciones por normas inferiores a la mencionada Ley.

En este supuesto, estaríamos ante un reglamento directamente inconstitucional. De acuerdo con Juan Carlos Morón, estos reglamentos son aquellos que "de manera inmediata transgrede(n), viola(n) o es(son) incompatible(s) con un precepto constitucional, como por ejemplo, un reglamento autónomo por su contenido viole algún derecho fundamental de los ciudadanos. ${ }^{25} \mathrm{El}$ mencionado artículo vulnera la Constitución en al menos dos momentos. El primero es la violación del artículo 2, inciso 5 de la Constitución Política del Perú que establece que todos tenemos derecho a solicitar y recibir información de las entidades de la Administración Pública, salvo en los casos que esta afecte la intimidad personal, esté excluida por la ley o por razones de seguridad nacional.

Como podemos deducir de lo contemplado hasta ahora, el párrafo del Reglamento del Decreto Legislativo 1353 que crea la nueva excepción a la Ley de Transparencia limita el derecho fundamental al acceso a la información pública y no lo hace bajo algunas de las modalidades contempladas por la Constitución. Como lo ha reconocido el Tribunal Constitucional, respecto de este derecho se reconocen dos variantes: una individual y una colectiva. La individual se corresponde con la posibilidad del solicitante para ejercer otros derechos y la colectiva está referida a la posibilidad de formar opinión pública y al control constitucional sobre los representantes de la sociedad. ${ }^{26}$ Por tanto, la nueva excepción planteada por el Reglamento del Decreto Legislativo 1353 no solo viola formalmente el precepto constitucional, sino que su efecto se extiende a los derechos conexos al ejercicio de acceso a la información pública.

La segunda trasgresión es la violación del artículo 51 de la Constitución Política del Perú,

23. Ibíd., 8.

24. Ibíd., 30.

25. Juan Carlos Morón, “Análisis jurisprudencial del Proceso de Acción Popular en el Perú: Propuestas para mejorar el control jurisdiccional sobre las normas reglamentarias". Tesis para optar por el grado académico de Magíster en Derecho con mención en Derecho Constitucional. (Lima: Pontificia Universidad Católica del Perú, Escuela de Posgrado, 2013) 115.

26. Sentencia del Expediente $\mathrm{N}^{\circ}$ 01797-2002 HD/TC, fundamento jurídico 11. 
que señala la primacía de nuestra Carta Magna sobre todas las normas legales y a su vez la primacía de estas sobre otras normas de menor jerarquía. Teniendo en cuenta que la situación descrita es la de un Reglamento que desnaturaliza lo establecido en una norma legal de mayor jerarquía, parece evidente cuál de ellas debe prevalecer en dicho conflicto. Al respecto el Tribunal Constitucional ha dicho lo siguiente:

"La fuerza normativa de la que está investida la Administración se manifiesta por antonomasia en el ejercicio de su potestad reglamentaria. El reglamento es la norma que, subordinada directamente a las leyes e indirectamente a la Constitución, puede, de un lado, desarrollar la ley, sin transgredirla ni desnaturalizarla, $y$, de otro, hacer operativo el servicio que la Administración brinda a la comunidad. Los primeros son los llamados reglamentos secundum legem, de ejecución, o reglamentos ejecutivos de las leyes, los cuales están llamados a complementar y desarrollar la ley que los justifica y a la que se deben. (...) $)^{127}$-el subrayado es nuestro-.

Ahora bien, decimos que existe una situación de desnaturalización o trasgresión en la medida en que el Reglamento del Decreto Legislativo 1353 ha contradicho una disposición muy clara de la Ley de Transparencia: la de no añadir nuevas excepciones al acceso a la información pública, salvo que estas sean introducidas por otra ley de igual jerarquía. Si bien este Reglamento desarrolla lo dispuesto por el Decreto Legislativo 1353, que sí es una norma de igual jerarquía que la Ley de Transparencia, en esta no se hace ninguna mención a nuevas excepciones o se establece algún nuevo régimen de tratamiento de la información contenida en correos electrónicos o aplicaciones de mensajería electrónica de funcionarios públicos.

De acuerdo a todo ello, podemos afirmar, efectivamente, que la antigua redacción del artículo $16-A$ era inconstitucional porque establecía una excepción al derecho de acceso a la información pública. Así, vulneraba tanto la Constitución como la Ley: la Constitución, al ser un reglamento que transgrede la Ley — siendo que existe una norma constitucional que proscribe ello-; y, la Ley, porque es un reglamento que lo transgrede y desnaturaliza totalmente: crea excepciones no permitidas.

Ahora bien, creemos que la actual redacción del mencionado artículo sigue siendo inconstitucional e ilegal. En primer lugar, cabe enunciar que la nueva formulación del Reglamento establece una categoría de información -información institucional de naturaleza pública- no prevista en la Ley. Tal como expusimos previamente, la información contenida en los correos electrónicos y aplicaciones electrónicas de funcionarios públicos entran dentro del supuesto de información pública que define la ley. Por lo tanto, el establecer la categoría de "información institucional de naturaleza pública" genera un nuevo supuesto de información no prevista en la norma. La información es pública siguiendo alguno de los criterios que enunciamos previamente, no tiene que ser "información institucional".

En segundo lugar, el Reglamento dispone que sea el funcionario titular del correo electrónico quien debe proporcionar la información solicitada, mientras que la Ley explícitamente establece que es el funcionario responsable designado por la entidad el que debe brindarla. Aún más, que sea el propio funcionario quien determine si la información es o no de acceso público pone en manos de un funcionario público el poder de clasificar, indirectamente, cierta información. Al momento de solicitar información contenida en los correos electrónicos, esta debería ser entregada por parte del funcionario responsable de transparencia de la entidad salvo que esta esté considerada dentro de alguno de los supuestos de excepción, sin importar la voluntad o no del funcionario titular del correo electrónico institucional. 
En tercer lugar, creemos que el actual artículo 16-A del Reglamento vulnera el principio constitucional de transparencia al hacer más gravoso el acceso a cierta información pública - que el funcionario titular del correo sea quien deba brindar la información solicitada-. Ello brinda mayor opacidad al actuar del Estado e incrementa la cultura del secretismo. Así, otorga una potestad discrecional al funcionario titular del correo electrónico, siendo que la entrega de información no es discrecional, sino que nace de una obligación constitucional de entregarla.

Para concluir, es importante recalcar que nosotros no sostenemos que pueda ser el caso que en las cuentas de correo electrónico institucionales exista información del funcionario público que pueda resultar sensible e incluso lesiva de su derecho a la intimidad o derecho de protección de datos personales. No obstante, el determinar ello no está en las manos del propio funcionario público, ni incluso en las manos del funcionario encargado de transparencia de la entidad.

Si la información cumple con alguno de los supuestos reseñados de manera anterior, es considerada información pública y debería ser entregada a quien la solicita salvo esta quepa dentro de algunas de las excepciones. De ser este el caso, la entidad debe motivar por qué no entrega la información en base a alguno de los supuestos de excepción; siendo que le debería corresponder al juez el decidir si, en efecto, la información no entregada está dentro de algunos supuestos de excepción. La decisión debería recaer, entonces, en manos de quien ejerza jurisdicción y garantice, conforme a ello, el cuidado necesario para tratar dicha información. 